\title{
Direct Injection of Redissolved Cell Culture Media into a Single-Column Liquid Chromatography Coupled to Mass Spectrometry for the Measure- ment of $\mathrm{PGE}_{2}$
}

\author{
Pedro Araujo ${ }^{*}$, Zhen-Yu Du, Thu-Thao Nguyen and Elisabeth Holen
}

National Institute of Nutrition and Seafood Research (NIFES), P.O. Box 2029 Nordnes, N-5817 Bergen, Norway

\begin{abstract}
The traditional approach to assessing eicosanoids in cell cultures by liquid or gas chromatography coupled to mass spectrometry involves time-consuming procedures such as derivatisation, degradation, solid-phase extraction, liquidliquid extraction, thin layer chromatography and sometimes, combination of all these procedures prior to the injection of the sample in the chromatography system. The performance of a method that allows the direct injection of redissolved cell culture media into a single-column liquid chromatography instrument coupled to mass spectrometry is evaluated. The external standard calibration curves were linear between 1-50 ng/ml for Williams' medium E and L-15 medium. The limit of detection and quantification were 0.5 and $1 \mathrm{ng} / \mathrm{ml}$ in both media respectively. The recovery values were $98.6 \%$ for Williams' medium E and $100.3 \%$ for L-15 medium. The internal standard method was not used for quantitative purposes due to the variability of the response factor. The proposed method has potential for broad implementation in monitoring biomarkers in cell cultures.
\end{abstract}

Keywords: Cell cultures, eicosanoids, prostaglandin $\mathrm{E}_{2}, \mathrm{LCMS}$, ion-trap mass spectrometry.

\section{INTRODUCTION}

Cell culture systems are suitable substitute methods for animal experiments. They have become increasingly important tools to investigate the production of eicosanoids, such as $\mathrm{PGE}_{2}$ in various types of cell lines. The concentration levels of $\mathrm{PGE}_{2}$ are an important criterion for the determination of pathophysiological events in invertebrates, vertebrates, and mammals [1]. Antibody-based assays such as enzyme-linked immunosorbent assay (ELISA) and radioimmunoassays are the most widely used methods for the estimation of $\mathrm{PGE}_{2}$. However, the main drawbacks of these assays are: trend to overestimate the levels of metabolites due to cross-reactivity with related compounds resulting in reduced selectivity, lack of specificity for complex biological fluids, variability in the quantification of sequential samples and limitation to the detection of a single product at the time $[2,3]$. Gas chromatography and liquid chromatography coupled to mass spectrometry (GCMS and LCMS respectively) have proved to be reliable techniques capable of preventing the problems associated with antibody-based assays. A study aiming at comparing ELISA and GC/MS revealed that the estimated concentrations of 8-isoprostaglandin $\mathrm{F}_{2 \alpha}$ by ELISA were 30 -fold greater than those determined by GCMS [2]. Nowadays, it is accepted that GCMS and LCMS outperform antibody-based techniques and they are commonly used in the determination of eicosanoids in a wide variety of samples, including cell cultures [3-6]. However, the determination of $\mathrm{PGE}_{2}$ in cell culture systems by GCMS or LCMS

*Address correspondence to this author at the National Institute of Nutrition and Seafood Research (NIFES), P.O. Box 2029 Nordnes, N-5817 Bergen, Norway; Tel: +47 95285039; Fax: +47 55905299;

E-mail: pedro.araujo@nifes.no demands some tedious and time-consuming preparation steps such as derivatisation, degradation, solid-phase extraction (SPE), liquid-liquid extraction (LLE), thin layer chromatography and sometimes, combination of all these procedures prior to the injection of the sample in the chromatography system. Thus, there has been a growing interest towards the development of simpler methods and improvement of the already existing sample protocols in terms of sensitivity, selectivity and simplicity of sample preparation. In some analytical areas, such as drug analysis, direct injection of a cell culture medium into the liquid chromatography system has been achieved by substituting the SPE and LLE steps for an automated on-line two-column-switching pre-concentration system [7]. Although, this proposed system is a reliable alternative to reduce sample preparation by enabling effective clean-up of cell cultures media, the required equipment is rather complex, involving a combination of several concentration and separation columns, pumps and switching valves under computer control. This significantly complicates the analysis and increases its cost. Direct injection of cell culture medium into a single column is generally overlooked in the analysis of eicosanoids due to the complexity of the culture medium which in turn can seriously affect the chromatography performance. The goal of this investigation is to propose a simple and efficient method that minimizes sample manipulation and allows the direct injection of redissolved cell culture samples into a single-column LCMS system. The investigation concentrates on the analysis of $\mathrm{PGE}_{2}$ produced by mammalian and fish cells and determined by using a LC isocratic system coupled to a tandem MS in negative mode. The $\mathrm{m} / \mathrm{z} 351$ signal corresponding to the ion $\left[\mathrm{PGE}_{2}-\mathrm{H}\right]^{-}$was isolated and fragmented and the identification and quantification carried out by extracting the ion fragment chromatograms at 333, 315 and $271 \mathrm{~m} / \mathrm{z}$. 


\section{EXPERIMENTAL}

\subsection{Reagents}

Prostaglandin E2 $\left(\mathrm{PGE}_{2}\right)$ and deuterated prostaglandin E2 $\left(\mathrm{PGE}_{2}-d_{4}\right)$ were from Cayman Chemical (Ann Arbor, MI, USA). Acetonitrile and methanol were from Merck (Darmstadt, Germany). De-ionized water was purified in a Milli-Q system (Millipore, Milford, MA).

\subsection{Cell Cultures}

\subsubsection{Hepatocyte Culture}

Hepatocytes isolated from Wistar rats (200-250 g) were attached to dishes with $60 \mathrm{~mm}$-diameter at a density of approximately $2 \times 10^{6}$ cells per dish and incubated in Williams' medium E (Sigma, St. Louis, MO) containing $10 \% \mathrm{v} / \mathrm{v}$ fetal bovine serum, and $1 \% \mathrm{v} / \mathrm{v}$ antibiotic antimycotic solution (Sigma, St. Louis, MO). After pre-incubation in an humified atmosphere $\left(5 \% \mathrm{CO}_{2}, 95 \%\right.$ air) for $3 \mathrm{~h}$ at $37{ }^{\circ} \mathrm{C}$, the medium was removed and the attached hepatocyte monolayer was washed gently with $3 \mathrm{ml}$ of fresh Williams' medium E (WME) without fetal bovine serum to remove the unattached and non-viable cells. The incubation began with the addition of $4 \mathrm{ml}$ of WME containing 1\% antibiotic antimycotic solution and $200 \mu \mathrm{M}$ of arachidonic acid bound to fatty acid-free bovine serum albumin (BSA) at a 4:1 molar ratio. Fatty acid peroxidation was prevented by adding $0.1 \%$ butylated hydroxytoluene and $20 \mu \mathrm{M} \alpha$-tocopheryl succinate into the culture medium. The cells were incubated for $24 \mathrm{~h}$ without changing the medium.

\subsubsection{Head Kidney Cultures}

Head kidney cells isolated from Atlantic cod (800-1000 g) were seeded into a 12 well plate (Corning, New York, USA) with a density of $3 \times 10^{6}$ cells per well. A volume of 2 $\mathrm{ml}$ of L-15 medium (Sigma, St. Louis, MO) consisting of $1 \%$ glutaMax (Gibco-BRL, Cergy-Pontoise, France), 1\% penicilline-streptomycine-amphotericine (BioWittaker, Petit Rechain, Belgium) and $10 \%$ fetal calf serum (BioWhittaker, Petit Rechain, Belgium) was added to each well. The cells were incubated at $9{ }^{\circ} \mathrm{C}$ in a normal atmosphere incubator for 7 days without changing the medium.

\subsection{Proposed Sample Preparation Protocol}

After incubating hepatocytes and head kidney cells for 24 and $168 \mathrm{~h}$ respectively, $3 \mathrm{ml}$ of the media (WME or L-15 medium) were centrifuged at $3000 \mathrm{~g}$ for $10 \mathrm{~min}$ at $4{ }^{\circ} \mathrm{C}$. An aliquot of $2 \mathrm{ml}$ of supernatant is collected and freeze dried in a Hetosicc system (Heto, Birkerød, Denmark). An aliquot of $1 \mathrm{ml}$ of acetonitrile was added to the dried sample, vortexmixed for $1 \mathrm{~min}$, centrifuged at $3000 \mathrm{~g}$ for $10 \mathrm{~min}$ and the supernatant collected. This step was repeated one more time. The collected supernatant was evaporated to dryness under nitrogen at room temperature and reconstituted in $30 \mu \mathrm{l}$ of acetonitrile, vortex-mixed for 30 seconds and submitted to LCMS/MS.

\subsection{Calibration}

The prediction capability of internal standard and external standard calibration curves in the quantification of $\mathrm{PGE}_{2}$ in the media was evaluated. The internal standard calibration curves were prepared as follows: two set of vials containing $50 \mu \mathrm{PGE}(1,15,25,35,50 \mathrm{ng} / \mathrm{ml})$ and a constant concen- tration of $\mathrm{PGE}_{2}-d_{4}(5 \mathrm{ng} / \mathrm{ml})$ in acetonitrile were prepared in triplicates and evaporated to dryness under a stream of nitrogen at room temperature. Aliquots of $50 \mu 1$ of fresh culture medium (WME or L-15), with not detectable levels of $\mathrm{PGE}_{2}$, were added into each set of vials and vortex-mixed for 2 $\min$. The solutions were treated according to the proposed sample preparation protocol. The external calibration curve was constructed in a similar way but without adding $\mathrm{PGE}_{2}-$ $d_{4}$.

\subsection{Liquid Chromatography Ion-Trap Mass Spectrome- try (LCITMS)}

The LCITMS used in this study was an Agilent 1100 series LC/MSD trap, SL model with an electrospray interface (ESI), a quaternary pump, degasser, autosampler, thermostatted column compartment, variable-wavelength UV detector and $25 \mu 1$ injection volume. A Zorbax Eclipse- $\mathrm{C}_{8}$ RP $150 \times 4.6 \mathrm{~mm}, 5 \mu \mathrm{m}$ column (Agilent, Palo Alto, USA) was used and kept in the column compartment at $40{ }^{\circ} \mathrm{C}$. The solvent system operated in isocratic mode at $0.2 \mathrm{ml} / \mathrm{min}$ was acetonitrile with formic acid $0.1 \%(\mathrm{v} / \mathrm{v})$ and UV detection at $254 \mathrm{~nm}$. The total analysis time was $60 \mathrm{~min}$. Nitrogen was used as nebulizing (50 psi) and drying gas $(8 \mathrm{l} / \mathrm{min})$ at 350 ${ }^{\circ} \mathrm{C}$. The ESI source was operated in negative ion mode and the ion optics responsible for getting the ions in the ion-trap such as capillary exit, skimmer, lens and octapoles voltages were controlled by using the Smart View option with a resolution of $13000 \mathrm{~m} / \mathrm{z} / \mathrm{sec}(\mathrm{FWHM} / \mathrm{m} / \mathrm{z}=0.6-0.7)$. Complete system control, data acquisition and processing were done using the ChemStation for LC/MSD version 4.2 from Agilent. The transitions monitored were $351 \rightarrow 333,315,271$ $m / z$ for $\mathrm{PGE}_{2}$ and $355 \rightarrow 337,319,275 \mathrm{~m} / z$ for $\mathrm{PGE}_{2}-d_{4}$ and their intensities were recorded in ion counts per second (icps).

\subsection{Statistics}

Data are expressed as mean values and standard deviations. The statistical significance of the regression analysis was determined by the $F$-test at a $95 \%$ confidence level using Statgraphics Plus 5.1.

\section{RESULTS AND DISCUSSION}

\subsection{Proposed Sample Preparation Method}

After stimulating by arachidonic acid for $24 \mathrm{~h}$, the medium of hepatocyte culture is dried and redissolved in acetonitrile as described above and injected into a single-column LCMS/MS system afterwards. The ion chromatogram of the released $\mathrm{PGE}_{2}$ was recorded by isolating the signal $351 \mathrm{~m} / \mathrm{z}$ and fragmenting it into the characteristic product ions $\left[\mathrm{PGE}_{2}-\mathrm{H}_{2} \mathrm{O}-\mathrm{H}\right],\left[\mathrm{PGE}_{2}-2 \mathrm{H}_{2} \mathrm{O}-\mathrm{H}\right]^{-}$and $\left[\mathrm{PGE}_{2}-2 \mathrm{H}_{2} \mathrm{O}-44-\mathrm{H}\right]^{-}$at 333,315 and $271 \mathrm{~m} / \mathrm{z}$ respectively (Fig. 1a). The results showed in Fig. (1a) were compared with those obtained by spiking a blank WME sample (containing only BSA) with a standard solution of $\mathrm{PGE}_{2}$ (Fig. 1b). The superimposition of the ion chromatograms of released $\mathrm{PGE}_{2}$ from hepatocytes and spiked $\mathrm{PGE}_{2}$ in blank medium, exhibits a perfect overlapping between the signals at 333, 315 and $271 \mathrm{~m} / \mathrm{z}$. Similar results were found when a sample of L-15 containing released $\mathrm{PGE}_{2}$ from head kidney cells incubated for 7 days (results not shown) and a sample of hepatocytes plus medium incubated for 14 days (Fig. 1c) were compared against spiked L-15 and WME respectively. These results give a 
a)

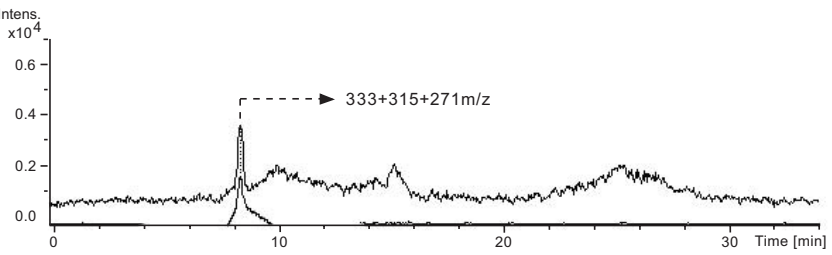

b)

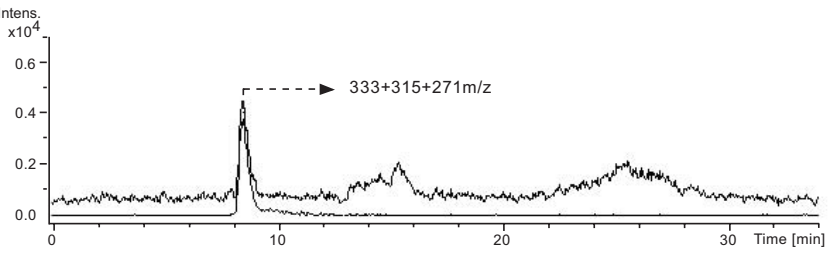

c)

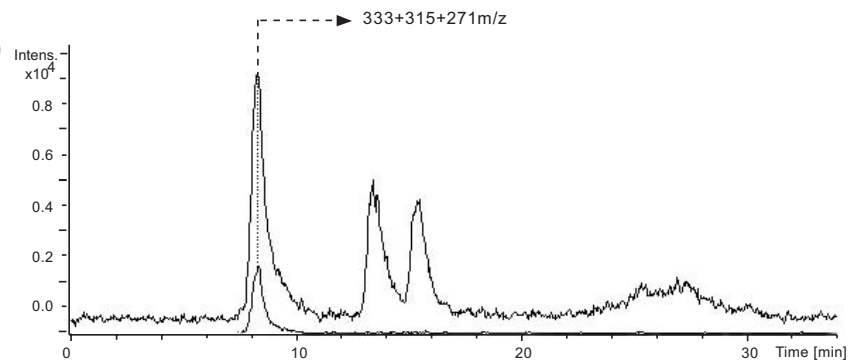

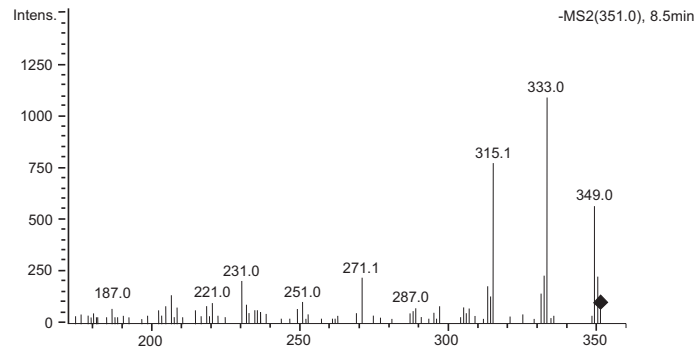
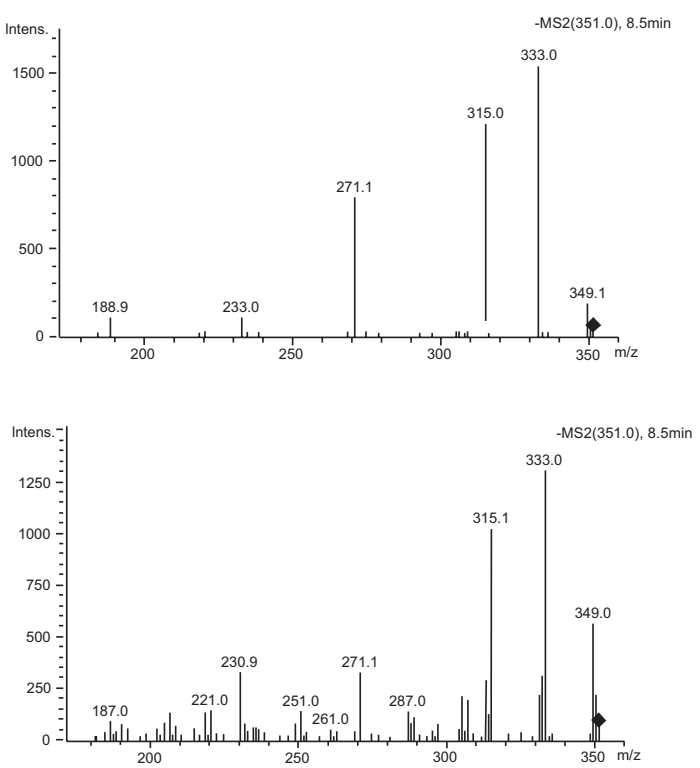

Fig. (1). Superimposed total ion current and extracted ion chromatograms (left) and corresponding ionization mass spectra (right) of (a) released $\mathrm{PGE}_{2}$ in Williams' medium E by hepatocyte cells incubated for $24 \mathrm{~h}$; (b) Williams' medium E spiked with $25 \mathrm{ng} / \mathrm{ml}$ of $\mathrm{PGE}_{2} ;(\mathbf{c})$ hepatocyte cells plus Williams' medium E incubated for 14 days.

clear indication that the sample protocol described in this article is suitable for determining $\mathrm{PGE}_{2}$ in cell culture systems either in mammalian or fish models.

\subsection{Internal Standard Calibration Studies}

Calibration graphs were constructed in two different blank matrices: WME and L-15 medium. Both media were treated according to the proposed sample preparation protocol. The internal standard calibration curve was prepared by spiking cell medium (WME or L-15) with different concentrations of $\mathrm{PGE}_{2}(1,15,25,35,50 \mathrm{ng} / \mathrm{ml})$ and keeping constant the concentration of the internal standard $\left(5 \mathrm{ng} / \mathrm{ml}\right.$ of $\left.\mathrm{PGE}_{2}-d_{4}\right)$. The preparation error was checked by preparing every calibration point in triplicates. The calibration graphs were constructed using least-squares regression of $\mathrm{PGE}_{2} / \mathrm{PGE} 2-d_{4}$ peak area ratios (designated as $\mathrm{S}_{\mathrm{PGE}_{2}} / \mathrm{S}_{\mathrm{PGE}_{2}-\mathrm{d}_{4}}$ ) against $\mathrm{PGE}_{2}$ concentrations (designated as $\left[\mathrm{PGE}_{2}\right]$ ). The analytical characteristic of the PGE 2 curves were $\mathrm{S}_{\mathrm{PGE}_{2}} / \mathrm{S}_{\mathrm{PGE}_{2}-\mathrm{d}_{4}}=0.41 \times$ [PGE2]-0.87 and $\mathrm{S}_{\mathrm{PGE}_{2}} / \mathrm{S}_{\mathrm{PGE}_{2}-\mathrm{d}_{4}}=0.52 \times[\mathrm{PGE} 2]-0.92$ with correlation coefficients of 0.995 and 0.996 for WME and L-15 medium respectively. Comparison of the theoretical and backcalculated $\mathrm{PGE}_{2}$ concentrations by using the peak area ratios and the analytical characteristic of the regression curves revealed recovery values that ranged between $270-83 \%$ and 225 $84 \%$ for WME and L-15 medium respectively when the concentration of $\mathrm{PGE}_{2}$ was varied between $1-15 \mathrm{ng} / \mathrm{ml}$ in both media (Fig. 2). These variable recovery values indicate very low accuracies at these levels of concentration in both media. Relatively constant recovery percentages averaging $99.6 \pm 5.0$ and $100.6 \pm 7.1 \%$ were observed between $25-50 \mathrm{ng} / \mathrm{ml}$ of $\mathrm{PGE}_{2}$ for WME and L-15 medium respectively (Fig. 2). The preparation error was not significant at the $95 \%$ confidence level.

\subsection{Response Factor Accuracy and Recovery}

In order to explain the low accuracies found between 1$15 \mathrm{ng} / \mathrm{ml}$ of $\mathrm{PGE}_{2}$ in the above experiments, the internal standard response factor was calculated at every experimental point by multiplying the $\mathrm{PGE}_{2} / \mathrm{PGE} 2-d_{4}$ concentration ratio by the PGE2- $d_{4} / \mathrm{PGE}_{2}$ area ratio. The regression of the calculated response factors against the concentrations of 


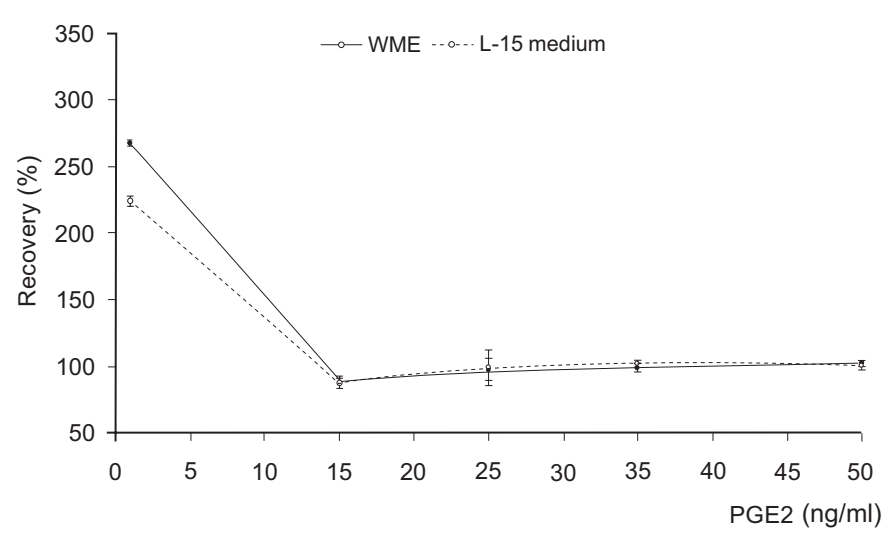

Fig. (2). Recovery of $\mathrm{PGE}_{2}$ in Williams' medium E and L-15 medium using the internal standard technique.

spiked $\mathrm{PGE}_{2}$ in both media (Fig. 3) reveals that the response factor does not remain constant throughout the analytical range considered. The dashed line in Fig. (3) illustrates the ideal behaviour of the response factor as a function of the analytical concentration. It is evident from Fig. (3) that the response factor (designated as RF) decreases logarithmically in both media as the concentration of $\mathrm{PGE}_{2}$ is increased, according to the equations $\mathrm{RF}=-0.10 \times \operatorname{Ln}\left[\mathrm{PGE}_{2}\right]+0.87$ and $\mathrm{RF}=-0.11 \times \operatorname{Ln}\left[\mathrm{PGE}_{2}\right]+0.81$ with regression coefficients of 0.973 and 0.987 for WME and L-15 medium respectively. The observed variability of the RF as a function of the $\mathrm{PGE}_{2}$ concentration between $1-15 \mathrm{ng} / \mathrm{ml}$ as well as its constancy between $25-50 \mathrm{ng} / \mathrm{ml}$ (Fig. 3) explain the different recovery values (and consequently the variability in accuracy) found at different $\mathrm{PGE}_{2}$ concentration ranges in the previous experiments. Recent findings on the variability of the response factor as a function of the concentration $[8,9]$ suggest that the degree of ionization of the internal standard in the electro-spray ion source and the interaction $\mathrm{PGE}_{2} / \mathrm{PGE} 2-d_{4}$ could be significant factors that affect the accuracy of the determination. The addition of $\mathrm{PGE}_{2}-d_{4}$ before submitting the sample to any treatment procedure can help to compensate for recovery losses, provided that the degree of ionization of the fixed amount of $\mathrm{PGE}_{2}-d_{4}$ is not affected by the amount of $\mathrm{PGE}_{2}$ in the entire analytical range investigated, in that way the response factor remains constant and the results are meaningful. In a recent comparative study between the internal standard and the traditional calibration method by using LCMS/MS [9], it is reported that the degree of ionization in the electro-spray ion source is strongly dependent on the amount of molecules resulting in a non-linearity in the concentration/response ratio. It must be said, that several quantitative studies [10-12] have demonstrated the variability of the RF as a direct result of varying the analyte and internal standard concentrations indicating clearly that among the possible variables affecting the RF accuracy, the interaction analyte/internal-standard could play an important role which is generally omitted in quantification studies.

\subsection{Direct Quantification of Cell Culture Media}

Based on the previous results, calibration curves were constructed by spiking separately fresh WME and L-15 me- dium with different concentrations of $\mathrm{PGE}_{2}(1-50 \mathrm{ng} / \mathrm{ml})$ without adding internal standard. Three replicates were prepared at each level of concentration. The calibration curves showed good linearity over the investigated concentration range with a correlation coefficient of 0.999 in both media and recovery values that ranged between $98.6 \pm 3.1 \%$ and $100.3 \pm 1.7 \%$ for WME and L-15 medium respectively. The preparation error checked in both media was not significant at the $95 \%$ confidence level. The limits of detection and quantification defined as the analytical concentration giving a signal equal to three and six times the standard deviation of the blank medium signal and calculated from the calibration curves were $0.5 \mathrm{ng} / \mathrm{ml}$ and $1 \mathrm{ng} / \mathrm{ml}$ respectively in both media. The released $\mathrm{PGE}_{2}$ into WME and L-15 medium by hepatocytes and head kidney cells, with and without stimulation ranged from 5.5 to $8.3 \mathrm{ng} / \mathrm{ml}$ and 3.4 to $30.2 \mathrm{ng} / \mathrm{ml} \mathrm{re-}$ spectively.

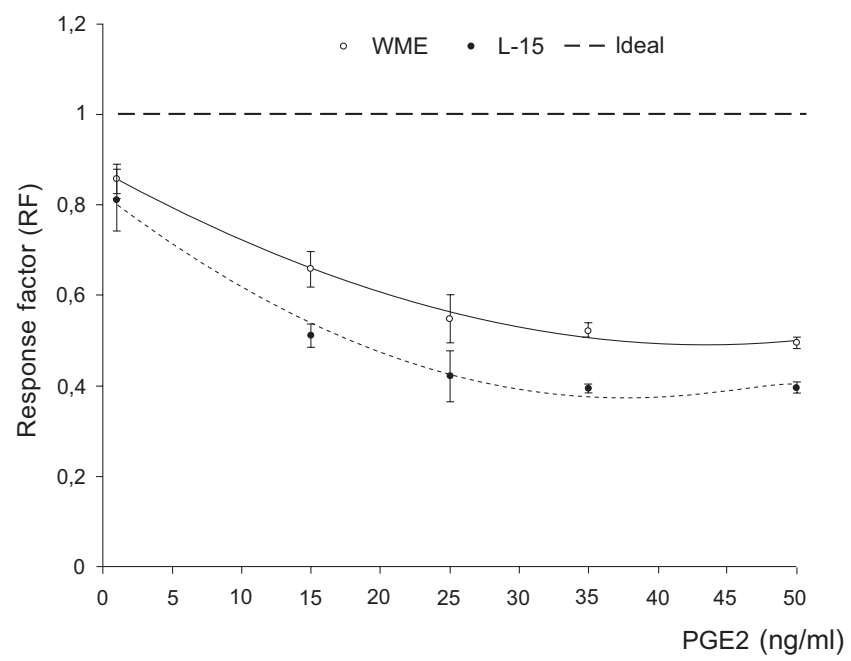

Fig. (3). Variability of the response factor as a function of the $\mathrm{PGE}_{2}$ concentration at a fixed level of $\mathrm{PGE}_{2}-d_{4}(5 \mathrm{ng} / \mathrm{ml})$ in Williams' medium E (solid line ) and L-15 medium (dotted line). The ideal behaviour is represented by a dashed line. Every point represents the average of 3 measurements.

\section{CONCLUSIONS}

Although the results obtained by using the internal standard method are less satisfactory than those obtained with the external standard method, it must be said that a comparison between both methodologies in the context of the present investigation is not appropriate considering that the internal standard method is affected by factors such as the interaction $\mathrm{PGE}_{2} /$ internal-standard which could not be estimated by the classical methodology used in the present work. By performing a multivariate study could be possible to determine systematically and simultaneously a $\mathrm{PGE}_{2}$ and $\mathrm{PGE}_{2}-\mathrm{d}_{4}$ concentration region where the response factor remains constant.

To our knowledge this is the first reported method that allows the direct injection of redissolved culture medium or culture medium containing cells into a single-column LCMS system. The proposed method is an effective, simple and rapid strategy for the analysis of $\mathrm{PGE}_{2}$ in cell cultures that minimizes sample manipulation and potential contamination, reduces the requirements for handling potentially infectious biomaterial and improves reproducibility and most impor- 
tantly, the proposed method has potential for broad implementation in monitoring biomarkers in cell cultures.

\section{ACKNOWLEDGEMENT}

This study is supported by the Norwegian Research Council (SIP project NRF 173534/I30).

\section{REFERENCES}

[1] Cha, Y. I.; Solnica-Krezel, L.; DuBois, R. N. Dev. Biol., 2006, 289, 263.

[2] Il'yasova, D.; Morrow, J. D.; Ivanova, A.; Wagenknecht, L. E. Ann. Epidemiol., 2004, 14, 793.

[3] Takabatake, M.; Hishinuma, T.; Suzuki, N.; Chiba, S.; Tsukamoto, H.; Nakamura, H.; Saga, T.; Tomioka, Y.; Kurose, A.; Sawai, T.; Mizugaki, M. Prostaglandins Leukot. Essent. Fatty Acids, 2002, 67,51 .
[4] Yang, P.; Felix, E.; Madden, T.; Fischer, S. M.; Newman, R. A. Anal. Biochem., 2002, 308, 168.

[5] Kempen, E. C.; Yang, P.; Felix, E.; Madden, T.; Newman, R. A. Anal. Biochem., 2001, 297, 183.

[6] Tsukamoto, H.; Hishinuma, T.; Mikkaichi, T.; Nakamura, H.; Yamazaki, T.; Tomioka, Y.; Mizugaki, M. J. Chromatogr. B., 2002, $774,205$.

[7] Oertel, R.; Richter, k.; Gramatte, T.; Kirch, W. J. Chromatogr. A., 1998, 797, 203.

[8] Nyadong, L.; Late, S.; Green, M. D.; Banga, A.; Fernández, F. M. J. Am. Soc. Mass Spectrom., 2008, 19, 380.

[9] Nilsson, L. B.; Eklund, G. J. Pharm. Biomed. Anal., 2007, 43 1094.

[10] Gregersen, K.; Frøyland, L.; Berstad, A.; Araujo, P. Talanta, 2008 75,466 .

[11] Araujo, P.; Bjørkkjær, T.; Berstad, A.; Frøyland, L. Prostaglandins Leukot. Essent. Fatty Acids, 2007, 77, 9

[12] Araujo, P.; Couillard, F.; Leirnes, E.; Ask, K.; Bøkevoll, A.; Frøyland L. J. Chromatogr. A, 2006, 112, 99. 